\title{
Maternal serum endoglin as an early marker of pre-eclampsia in high-risk patients
}

This article was published in the following Dove Press journal:

International Journal of Women's Health

25 September 2012

Number of times this article has been viewed

\author{
Tarek M Elhawary' \\ Aml S El-Bendary ${ }^{2}$ \\ Hala Demerdash ${ }^{3}$ \\ 'Department of Obstetrics and \\ Gynecology and Department of \\ Clinical Pathology, ${ }^{2}$ Faculty of \\ Medicine, Tanta University, Tanta, \\ ${ }^{3}$ Alexandria Main University Hospital, \\ Alexandria, Egypt
}

Background: Pre-eclampsia is a potentially serious condition that still accounts for significant morbidity and mortality for the affected mother and neonate. Although the pathogenesis is not fully understood, it is now widely accepted that vascular endothelial dysfunction is the most important and principal event in the pathophysiology of the disease. The aims of our study were to compare serum soluble endoglin levels at week 13 in normotensive pregnant women and in high-risk women, to determine whether the maternal plasma soluble endoglin concentration at 26 weeks is increased in pregnancies that subsequently develop pre-eclampsia, and to identify if soluble endoglin measurement improves the results of screening for pre-eclampsia.

Methods: This work was conducted in 60 healthy pregnant controls and 110 pregnant women at high risk for pre-eclampsia. Gestational age was confirmed by date of last menstrual period and first trimester ultrasound. The time of onset of pre-eclampsia was defined as the time of first elevated blood pressure or urinary protein measurement leading to the diagnosis. Blood samples were collected for measurement of soluble endoglin and other routine laboratory tests, including measurement of urinary proteins. Serum soluble endoglin was estimated by sandwich enzyme-linked immunosorbent assay.

Results: There was a highly significant increase in serum soluble endoglin in high-risk women compared with controls at week $13(P<0.001)$. Further determination of soluble endoglin revealed a more significant increase in women who developed early-onset pre-eclampsia compared with those who developed late-onset pre-eclampsia. Moreover, a significant positive correlation was found between soluble endoglin and both diastolic blood pressure and total urinary protein, ie, severity of pre-eclampsia.

Conclusion: Estimation of serum soluble endoglin at gestational week 13 could be used as a sensitive screening test for women at high risk of developing pre-eclampsia prior to onset of its clinical manifestations, which could potentially improve the outcome of pregnancy.

Keywords: pregnancy, pre-eclampsia, high risk, gestational age, endoglin

\section{Introduction}

Pre-eclampsia is a multisystem pregnancy-specific hypertensive syndrome that causes substantial maternal and fetal morbidity and mortality. The lack of an effective test for identification of women at risk of developing pre-eclampsia remains a factor contributing to the high morbidity of the disease. In most developing countries where the incidence of the disease is high, women present late with complications. ${ }^{1}$

Although pre-eclampsia is known as "the disease of theories", overwhelming evidence points to endothelial dysfunction as a central mechanism in the pathogenesis of the maternal syndrome of pre-eclampsia. The causes of this endothelial
Correspondence: Tarek M Elhawary

Department of Obstetrics and

Gynecology, Tanta University, 3/527

Elgeish Street, Tanta, Egypt

Tel +20 40335924 I

Fax +20 403359242

Email thawary4@yahoo.com 
dysfunction remain elusive. However, poor placentation has been proposed as a major factor. ${ }^{2}$

An ischemic placenta secretes soluble factors into the maternal vasculature which have been implicated in inducing endothelial dysfunction and the clinical features of pre-eclampsia. Excess secretion of a naturally occurring antiangiogenic molecule of placental origin, referred to as soluble endoglin, may contribute to the pathogenesis of pre-eclampsia. Soluble endoglin acts by antagonizing an angiogenic and vasodilator molecule known as transforming growth factor beta-1, which is important not only in angiogenesis but also in keeping the lining of the blood vessels healthy. As a result, the cells lining the blood vessels begin to sicken and die, blood pressure increases, and the blood vessels leak protein into the tissues and urine. ${ }^{3}$

The aims of this study were to compare serum soluble endoglin levels in normotensive pregnant women and in highrisk women at gestational week 13, to investigate whether the maternal plasma soluble endoglin concentration is increased at 26 weeks in pregnancies that are subsequently complicated by pre-eclampsia, and to determine whether inclusion of soluble endoglin levels improves the performance of screening for pre-eclampsia.

\section{Materials and methods}

The study was conducted at the Department of Obstetrics and Gynecology, Faculty of Medicine, Tanta University, and recruited women attending the antenatal care unit prior to week 12 of gestation and at increased risk of developing pre-eclampsia, so as to select pregnant pre-eclamptic women. All women signed a fully informed written consent to participate in the study.

The women were examined between January 2009 and September 2010, and comprised 170 singleton pregnancies. The inclusion criteria were at least one of the following risk factors for pre-eclampsia: a history of pre-eclampsia in a previous pregnancy, nulliparity, chronic hypertension, chronic renal disease, diabetes mellitus, and obesity (body mass index $\geq 30 \mathrm{~kg} / \mathrm{m}^{2}$ ). Exclusion criteria included multiple pregnancies, major fetal anomaly, placenta previa, and hepatitis. Gestational age was established on the basis of menstrual dates and confirmed by first trimester ultrasonography. Throughout their antenatal visits, the women were categorized into two groups, ie, a high-risk group $(\mathrm{n}=110)$ and a healthy control group (60 cases). In the highrisk group, diagnostic criteria for pre-eclampsia were identified in 35 cases who subsequently developed pre-eclampsia and in 45 cases who developed gestational hypertension. The control group comprised 60 normotensive controls unaffected by pre-eclampsia or gestational hypertension.

All women underwent detailed history-taking, a general physical, systemic, and obstetric examination, ultrasonographic abdominal evaluation, hematology testing, and urinary estimation of protein and sugar. Proteinuria was measured by dipstick test and was graded as $1+(30 \mathrm{mg} / \mathrm{dL})$, $2+(100 \mathrm{mg} / \mathrm{dL}), 3+(300 \mathrm{mg} / \mathrm{dL})$, or $4+(>2000 \mathrm{mg} / \mathrm{dL})$. Routine laboratory estimation of uric acid, urea, creatinine, aspartate transaminase, and alanine transaminase was done, along with a complete blood count. A serum soluble endoglin level was measured in all patients at weeks 13 and 26 using an enzyme-linked immunosorbent assay technique with reagents provided by Quantikine R\&D International (Minneapolis, MN). ${ }^{4}$

Pre-eclampsia was defined as a diastolic blood pressure $\geq 90 \mathrm{mmHg}$ and proteinuria of $\geq 1+(30 \mathrm{mg} / \mathrm{dL})$ on dipstick testing at gestational week 20 . In women with chronic hypertension, the diagnosis of pre-eclampsia was made by new-onset proteinuria after gestational week 20 . In women with chronic renal disease, diagnosis of pre-eclampsia was made by new-onset hypertension and worsening proteinuria after gestational week 20. Severe pre-eclampsia was defined as pre-eclampsia with either severe hypertension (diastolic blood pressure $\geq 110 \mathrm{mmHg}$ ), severe proteinuria (urinary protein excretion $\geq 3.5 \mathrm{~g}$ per 24 hours, findings of $\geq 3+$ [300 $\mathrm{mg} / \mathrm{dL}]$ ) on dipstick testing, or HELLP (hemolysis, elevated liver enzyme levels, low platelet count) syndrome. Time of onset of pre-eclampsia was defined as the time of first elevated blood pressure or urinary protein measurement leading to diagnosis of pre-eclampsia. ${ }^{5}$

\section{Statistical analysis}

Statistical analysis was done using the mean, standard error, Student's $t$-test, Chi-square, linear correlation coefficient, and analysis of variance tests by SPSS version 17 (SPSS Inc, Chicago, IL). An analysis of variance test was used for comparison of quantitative data from different time points in the same patient group.

\section{Results}

In the high-risk group, 35 women developed pre-eclampsia and 45 women were categorized as having gestational hypertension during the study period. At the time of study enrollment, baseline characteristics did not differ significantly between the study and control groups for age, body weight, height, and body mass index. However, women who subsequently developed pre-eclampsia had higher systolic and diastolic 
blood pressures at the first prenatal visit, and as expected, blood pressure levels were considerably higher when overt disease occurred. At the time of development of pre-eclampsia, the high-risk women developed significantly higher blood pressure and proteinuria compared with control women (Table 1).

All patients in group 2 were hypertensive at the time of enrolment. In contrast, all women in group 1 were normotensive. Both systolic and diastolic blood pressure was significantly higher in group 2 than in group 1 . At enrolment, three women $(2.7 \%)$ in group 2 had a trace of protein in their urine, two women $(1.8 \%$ ) had proteinuria $\leq 100 \mathrm{mg} / \mathrm{dL}$, three women $(2.7 \%)$ had $>100 \mathrm{mg} / \mathrm{dL}$, and five women (4.5\%) had $30-100 \mathrm{mg} / \mathrm{dL}(P<0.001)$. In contrast, only four women $(6.7 \%)$ in group 1 had proteinuria of $30-100 \mathrm{mg} / \mathrm{dL}$ which disappeared on follow-up visits.

Mean serum endoglin levels estimated at gestational week 13 were significantly higher in the high-risk group compared with the healthy control group, and significantly higher mean serum endoglin levels in women who developed early onset pre-eclampsia compared to those who developed late onset pre-eclampsia during follow-up of cases. Serum endoglin levels estimated at gestational week 13 showed a significant negative correlation with body weight $(\mathrm{r}=-0.468$, $P=0.023)$ and body mass index $(\mathrm{r}=-0.522, P=0.016)$, and a significant positive correlation with systolic blood pressure (r $=0.446, P=0.029$ ). Moreover, elevated serum soluble endoglin at gestational week 13 showed a significant positive correlation ( $\mathrm{r}=0.523, P=0.016)$ with a risk of pre-eclampsia. There was a positive correlation between serum endoglin levels and other parameters (gestational age, systolic blood pressure, diastolic blood pressure, urinary protein, serum creatinine, alanine transaminase) when measured at gestational week 26 . On the other hand, there was a negative correlation between serum endoglin levels and platelet count (Table 2).

In the present study, sequential estimation of serum endoglin revealed that the extent of increased serum soluble endoglin at gestational week 26 versus week 13 could specifically identify women liable to develop pre-eclampsia. Women in group 2 who developed pre-eclampsia were significantly more likely to deliver smaller babies at lower gestational ages and to deliver by cesarean section. The gestational age at delivery was 38-42 weeks in group 1 and 34-40 weeks in group 2a (high-risk women who did not develop pre-eclampsia), and 28-40 weeks in group $2 \mathrm{~b}$ (high-risk women who developed pre-eclampsia). Forty-three $(57.3 \%)$ women in group $2 \mathrm{a}$ had a vaginal delivery and the remaining women were delivered by cesarean section, with $16(45.7 \%)$ women in group $2 \mathrm{~b}$ having a vaginal delivery and the remaining women being delivered by cesarean section. Fifty-two (86.7\%) women in group 1 had a vaginal delivery and the remainder were delivered by cesarean section. None of the women in group 1 delivered before 37 weeks. Two women $(5.7 \%)$ in group $2 b$ had HELLP syndrome. The mean weight of neonates in groups $2 \mathrm{a}$ and $2 \mathrm{~b}$ was $2.96 \pm 0.23 \mathrm{~kg}$ and $2.45 \pm 0.86 \mathrm{~kg}$, respectively, and in group 1 was $3.32 \pm 0.74 \mathrm{~kg}$ (Table 3$)$.

\section{Discussion}

Pre-eclampsia is a multisystem disorder that causes substantial maternal and fetal morbidity and mortality. It is defined as a sudden onset of hypertension presenting after gestational week 20 ( $\geq 140 / 90 \mathrm{mmHg}$ ), accompanied by abnormal edema and/or proteinuria., 2,6

In our study, pregnant women classified as being at high risk for pre-eclampsia at week 13 had significantly higher serum endoglin levels compared with healthy pregnant controls. These results are in agreement with the results of Levine et al and Lim et al who found a positive correlation between circulating angiogenic factors, transforming growth factor beta-1, and development of pre-eclampsia. ${ }^{7,8}$ Moreover, a longitudinal study of 46 normotensive pregnancies at 8-40 weeks' gestation reported that the maternal plasma soluble endoglin concentration remained relatively stable until 25 weeks and then increased thereafter until term. ${ }^{9}$

Table I Clinical data of the entire study population at week I 3 (time of enrolment)

\begin{tabular}{|c|c|c|c|}
\hline & Group I (control group) & Group 2 (high-risk group) & $P$ value \\
\hline Patient age (years) & $23.20 \pm 4.96$ & $25.67 \pm 5.94$ & 0.233 \\
\hline Body weight (kg) & $73.47 \pm 3.79$ (69-9l) & $78.80 \pm 3.43(72-93)$ & 0.136 \\
\hline Height $(\mathrm{cm})$ & $163.54 \pm 3.17(158-173)$ & $161.27 \pm 3.45(156-171)$ & 0.227 \\
\hline $\mathrm{BMI}\left(\mathrm{kg} / \mathrm{m}^{2}\right)$ & $30.8 \pm 1.89(26.86-32.55)$ & $32.5 \pm 2.23(27.54-35.75)$ & 0.305 \\
\hline Systolic blood pressure $(\mathrm{mmHg})$ & $115.2 \pm 8(105-125)$ & $130.75 \pm 10.60(125-140)$ & $0.038 *$ \\
\hline Diastolic blood pressure $(\mathrm{mmHg})$ & $75 \pm 1.8(60-77)$ & $77 \pm 5.2(70-79)$ & $0.043^{*}$ \\
\hline Serum endoglin (pg/L) & $1025.0 \pm 104.62$ & $1760.0 \pm 200.43$ & $0.0336^{*}$ \\
\hline
\end{tabular}

Notes: Data are presented as the mean \pm standard deviation, ranges are in parentheses. *Significant difference versus control group. Abbreviation: BMI, body mass index. 
Table 2 Comparison between the studied groups as regards serum alanine transaminase, platelet count, and serum endoglin levels at week 26

\begin{tabular}{|c|c|c|c|c|c|}
\hline & $\begin{array}{l}\text { Group I } \\
\text { (controls) }\end{array}$ & $\begin{array}{l}\text { Group } 2 \\
\text { (gestational hypertension) }\end{array}$ & $\begin{array}{l}\text { Group } 3 \\
\text { (pre-eclampsia) }\end{array}$ & $P$ value & Tukey's test \\
\hline Alanine transaminase (IU/L) & $20.667 \pm 3.697$ & $24.933 \pm 5.625$ & $30.267 \pm 7.630$ & $<0.00 I^{*}$ & $\begin{array}{l}\text { Groups } 1 \text { and } 3 \\
\text { Groups } 2 \text { and } 3\end{array}$ \\
\hline Platelet count $\left(\times 10^{3}\right)$ & $190.333 \pm 13.819$ & $213.333 \pm 57.373$ & $167.667 \pm 38.539$ & $0.014^{*}$ & $\begin{array}{l}\text { Groups } 1 \text { and } 3 \\
\text { Groups } 2 \text { and } 3\end{array}$ \\
\hline Serum creatinine $(\mathrm{mg} / \mathrm{dL})$ & $\mathrm{I} .2 \pm 0.32$ & $\mathrm{I} .5 \pm 0.76$ & $2.4 \pm 0.81$ & $0.023 *$ & Groups I, 2, and 3 \\
\hline Serum endoglin (pg/L) & $1220.0 \pm 207.709$ & $2060.0 \pm 301.899$ & $2353.33 \pm 443.793$ & $<0.00 I^{*}$ & $\begin{array}{l}\text { Groups } 1 \text { and } 2 \\
\text { Groups } 2 \text { and } 3\end{array}$ \\
\hline
\end{tabular}

Our study revealed a significant positive correlation between soluble endoglin and blood pressure as well as total urinary proteins. This correlation is explained by the findings of Venkatesha et al who demonstrated that soluble endoglin acts by antagonizing an angiogenic molecule known as transforming growth factor beta-1, which is important in mediating nitric oxide-dependent vasodilatation and in keeping the lining of blood vessels healthy. ${ }^{10}$ Therefore, excess secretion of soluble endoglin leads to severe vasoconstriction, with resulting hypertension, and leakage of proteins into the tissues and urine..$^{11,12}$

Experimental evidence further supports the contribution of soluble endoglin to the pathogenesis of pre-eclampsia. Venkatesha et al also reported that exogenous soluble endoglin administration in pregnant rats leads to severe preeclampsia, including the HELLP syndrome and restriction of fetal growth. They stated that soluble endoglin increased the likelihood of HELLP syndrome in both the rat model and human pre-eclampsia. ${ }^{10}$

Our data show a significant positive correlation between soluble endoglin measured at week 13 in the high-risk group and the risk of pre-eclampsia with regard to systolic blood pressure and body mass index. These data indicate a relationship between serum soluble endoglin and constitutional data and with the severity of pre-eclampsia. Our results were in agreement with those reported by Hirashima et al,

Table 3 Pregnancy outcome in study groups

\begin{tabular}{|c|c|c|c|c|}
\hline & Group I & Group Ia & Group 2b & $P$ \\
\hline $\begin{array}{l}\text { Gestational } \\
\text { age }\end{array}$ & 38-42 weeks & $34-40$ weeks & 28-40 weeks & $\begin{array}{l}0.00 I^{*} \\
I \text { and } 2 a, 2 b \\
2 a \text { and } 2 b\end{array}$ \\
\hline $\begin{array}{l}\text { Vaginal } \\
\text { delivery }\end{array}$ & $86.7 \%$ & $57.3 \%$ & $45.7 \%$ & $\begin{array}{l}0.013 \\
1,2 a \text { and } 2 b\end{array}$ \\
\hline $\begin{array}{l}\text { Weight of } \\
\text { neonates }\end{array}$ & $3.32 \pm 0.74$ & $2.96 \pm 0.23$ & 2. $45 \pm 0.86$ & $\begin{array}{l}0.046 \\
1,2 a \text { and } 2 b\end{array}$ \\
\hline Still birth & 1.67 & 1.33 & 8.57 & $\begin{array}{l}0.000 \mathrm{I} \\
\mathrm{I}, 2 \mathrm{a} \text { and } 2 \mathrm{~b}\end{array}$ \\
\hline
\end{tabular}

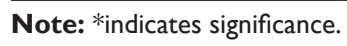

Toporsian et al, and Duhan et al, ${ }^{12-14}$ who found significantly elevated serum soluble endoglin in pre-eclamptic women in later pregnancy than in early pregnancy, together with a reduction in the angiogenic proteins, vascular endothelial growth factor and placental growth factor, and a general increase in antiangiogenic proteins, ie, soluble endoglin and soluble fms-like tyrosine kinase $1 .^{12-14}$

On the other hand, Gu et al performed a cross-sectional analysis at 4-week intervals of gestational age to evaluate the pattern of change in soluble endoglin levels among healthy women during normal pregnancy. They showed that soluble endoglin levels were stable until 33 weeks of gestation and then increased. ${ }^{15}$

This finding is further supported by Robinson and Johnson, who found in their longitudinal analysis of serum soluble endoglin in pregnant women, that in specimens obtained before the onset of pre-eclampsia for women in whom early-onset pre-eclampsia subsequently developed, soluble endoglin began to rise at $17-20$ weeks' gestation $(P<0.001)$, with a steep rise at 33-36 weeks. ${ }^{16}$ Salahuddin et al added that this dramatic elevation in circulating soluble endoglin in pregnant women who experienced early-onset pre-eclampsia highlights the role of this placental-derived protein in the development of the disorder. ${ }^{17}$

Our data show that patients with pre-eclampsia are likely to have a poorer pregnancy outcome, with more small for gestational age neonates, preterm delivery, and still births. These results are in agreement with those of Lee et al, ${ }^{18}$ who concluded that both soluble fms-like tyrosine kinase 1 and soluble endoglin are useful for diagnosing patients with pre-eclampsia and that serum levels of these factors may not correlate with poor prenatal outcomes. Another study found that serum soluble endoglin levels were significantly higher in early-onset compared with late-onset pre-eclampsia. ${ }^{19}$ However, other studies have suggested that elevated soluble endoglin may be a mechanism in other obstetric syndromes as well, such as fetal death and small for gestational 
age neonates..$^{20,21}$ Levine et al reported that normotensive patients who delivered a small for gestational age neonate had a higher maternal serum concentration of soluble endoglin compared with controls beginning at 17-20 weeks of gestation, and the difference was higher at 37-42 weeks. ${ }^{3}$

Most of the relevant studies done have been retrospective with limited numbers of patients. Thus, the evidence is insufficient to recommend the use of soluble endoglin for screening in early cases of pre-eclampsia. ${ }^{20}$ Prospective studies with a rigorous methodology and greater numbers of pre-eclamptic patients are needed to evaluate the clinical utility of this marker further, given that mechanisms responsible for pre-eclampsia will favor development of therapeutic strategies for the disease. Because there is no proven effective method for prevention of pre-eclampsia, early identification of women at high risk could potentially improve the outcome of pregnancy. Intensive maternal and fetal monitoring in such patients may prevent the development of serious complications.

In conclusion, estimation of serum soluble endoglin at gestational week 13 could be used as a sensitive screening test for high-risk women liable to develop pre-eclampsia prior to onset of its clinical manifestations, and could potentially improve the outcome of pregnancy.

\section{Disclosure}

The authors report no conflicts of interest in this work.

\section{References}

1. Levine RJ, Lam C, Qian C, et al. Soluble endoglin and other circulating antiangiogenic factors in pre-eclampsia. Obstet Gynecol Surv. 2007;62: 82-83.

2. Sharon M, Franklin H, Epstein S, et al. Pre-eclampsia and angiogenic imbalance. Annu Rev Med. 2010;59:61-78.

3. Levine RJ, Lam C, Qian C, et al. Soluble endoglin and other circulating anti-angiogenic factors in pre-eclampsia. $N$ Engl J Med. 2006;355:992-1005.

4. Chernecky CC. Laboratory Tests and Diagnostic Procedures. 3rd ed. Philadelphia, PA: WB Saunders; 2007.

5. American College of Obstetrics and Gynecology Practice Bulletin. Diagnosis and management of pre-eclampsia and eclampsia. Obstet Gynecol. 2002;99:159-167.
6. Foidart J, Munaut C, Chantraine F, Akolekar R, Nicolaides KH. Maternal plasma soluble endoglin at 11-13 weeks' gestation in pre-eclampsia. Ultrasound Obstet Gynecol. 2010;35:680-687.

7. Levine RJ, Maynard SE, Qian C. Circulating angiogenic factors and the risk of pre-eclampsia. $N$ Engl J Med. 2004;350:672-683.

8. Lim JH, Kim SY, Park SY, et al. Soluble endoglin and transforming growth factor-beta1 in women who subsequently developed pre-eclampsia. Prenat Diagn. 2009;29:471-476.

9. Romero R, Nien JK, Espinoza J, et al. A longitudinal study of angiogenic (placental growth factor) and anti-angiogenic (soluble endoglin and soluble vascular endothelial growth factor receptor-1) factors in normal pregnancy and patients destined to develop preeclampsia and deliver a small for gestational age neonate. J Matern Fetal Neonatal Med. 2008;21:9-23.

10. Venkatesha S, Toporsian M, Lam C. Soluble endoglin contributes to the pathogenesis of pre-eclampsia. Nat Med. 2006;12:642-649.

11. Masuyama $H$, Nakatsukasa $H$, Takamoto $N$, et al. Correlation between soluble endoglin, vascular endothelial growth factor receptor-1, and adipocytokines in pre-eclampsia. J Clin Endocrinol Metab. 2009;92: 2672-2679.

12. Hirashima C, Ohkuchi A, Arai F. Establishing reference values for both total soluble fms-like tyrosine kinase 1 and free placental growth factor in pregnant women. Hypertens Res. 2009;28:727-732.

13. Toporsian M, Gros R, Kabir MG. A role for endoglin in coupling eNOS activity and regulating vascular tone revealed in hereditary hemorrhagic telangiectasia. Circ Res. 2009;96:684-692.

14. Duhan N, Sharma D, Garg N, Dahiya K, Sirohiwal D. Comparative evaluation of serum endoglin in pre-eclampsia and normotensive pregnant women. Journal of Physiology and Pathophysiology. 2011;2:47-51.

15. Gu Y, Lewis DF, Wang Y. Placental productions and expressions of soluble endoglin, soluble fms-like tyrosine kinase receptor-1, and placental growth factor in normal and pre-eclamptic pregnancies. J Clin Endocrinol Metab. 2010;93:260-266.

16. Robinson CJ, Johnson DD. Soluble endoglin as a second-trimester marker for pre-eclampsia. Am J Obstet Gynecol. 2009;197:174-175.

17. Salahuddin S, Lee Y, Vadnais M, et al. Diagnostic utility of soluble fms-like tyrosine kinase 1 and soluble endoglin in hypertensive diseases of pregnancy. Obstetric Anesthesia Digest. 2010;28:19-20.

18. Lee HB, Kil KC, Nam SY, Shin JE, Cheon JY, Lee Y. Clinical usefulness of soluble fms-like tyrosine kinase 1, soluble endoglin and placental growth factor in Korean women with pre-eclampsia. Korean J Obstet Gynecol. 2011;54:229-235.

19. Fang M, He Y, Li H, Wu M, Shi X, Du H. Alterations of serum and placental endoglin in pre-eclampsia. $J$ Int Med Res. 2010;38:43-51.

20. Widmer M, Villar J, Benigni A, Conde-Agudelo A, Karumanchi SA, Lindheimer M. Mapping the theories of preeclampsia and the role of angiogenic factors: a systematic review. Obstet Gynecol. 2007;109: $168-180$.

21. Chaiworapongsa T, Romero R, Espinoza J, et al. Evidence supporting a role for blockade of the vascular endothelial growth factor system in the pathophysiology of preeclampsia. Young Investigator Award. Am J Obstet Gynecol. 2004;190:1541-1547.
International Journal of Women's Health

\section{Publish your work in this journal}

The International Journal of Women's Health is an international, peerreviewed open-access journal publishing original research, reports, reviews and commentaries on all aspects of women's healthcare including gynecology, obstetrics, and breast cancer. Subject areas include: Chronic conditions (migraine headaches, arthritis, osteoporosis);

\section{Dovepress}

Endocrine and autoimmune syndromes; Sexual and reproductive health; Psychological and psychosocial conditions. The manuscript management system is completely online and includes a very quick and fair peer-review system. Visit http://www.dovepress.com/ testimonials.php to read real quotes from published authors. 